\title{
Analysis of postoperative cognitive dysfunction and influencing factors of dexmedetomidine anesthesia in elderly patients with colorectal cancer
}

\author{
JINGCHAO ZHANG ${ }^{1}$, GUOQING LIU ${ }^{2}$, FANGXIANG ZHANG ${ }^{1}$, HUA FANG ${ }^{1}$, \\ DUWEN ZHANG $^{1}$, SHUCHUN LIU ${ }^{1}$, BINGNING CHEN $^{1}$ and HONG XIAO ${ }^{3}$ \\ ${ }^{1}$ Department of Anesthesiology, Guizhou Provincial People's Hospital, Guiyang, Guizhou 550002; \\ ${ }^{2}$ Department of Anesthesiology, Jinan Zhangqiu District Hospital of TCM, Jinan, Shandong 250200; \\ ${ }^{3}$ Department of Anesthesiology, Xiamen Hospital of Traditional Chinese Medicine, Xiamen, Fujian 361001, P.R. China
}

Received February 5, 2019; Accepted May 28, 2019

DOI: $10.3892 / \mathrm{ol} .2019 .10611$

\begin{abstract}
Effect of dexmedetomidine-assisted general anesthesia on early postoperative cognitive dysfunctions in elderly patients with colorectal cancer was explored. In total, 140 patients with radical colorectal cancer under general anesthesia from March 2012 to June 2015 were enrolled in the Guizhou Provincial People's Hospital, including 80 patients in the dexmedetomidine group and 60 patients in the saline group. Surgery conditions were recorded, and the incidence of postoperative cognitive dysfunction (POCD) and cognitive function score (MMSE score) were compared between the two groups. Serum levels of S-100 $\beta$ protein $(S-100 \beta)$ and interleukin-6 (IL-6) were measured by enzyme-linked immunosorbent assay. The anesthesia time and intraoperative blood loss in the experiment group were significantly lower than those in the control group $(\mathrm{P}<0.05)$. The MMSE scores of the two groups on the 1st and 3rd day after surgery were lower than those before surgery $(\mathrm{P}<0.05)$. The incidence rates of the experiment group were significantly lower than that of the control group $(\mathrm{P}<0.05)$. The levels of serum IL-6 and S-100 $\beta$ were increased on the 1st and 3rd day after surgery compared with those before surgery $(\mathrm{P}<0.05)$. The levels of serum IL-6 and $\mathrm{S}-100 \beta$ in the control group were significantly higher than those in the experiment group on the 1st and 3rd day after surgery $(\mathrm{P}<0.05)$. Age, duration of anesthesia, intraoperative blood loss, expression of IL- 6 and S-100 $\beta$ were the influencing factors of POCD. Age $\geq 70$ years, anesthesia duration $\geq 3 \mathrm{~h}$, intraoperative blood loss $\geq 350 \mathrm{ml}$, and high expression of IL- 6 and S-100 $\beta$ was an important factor related to the occurrence
\end{abstract}

Correspondence to: Dr Hong Xiao, Department of Anesthesiology, Xiamen Hospital of Traditional Chinese Medicine, 1739 Xianyue Road, Huli, Xiamen, Fujian 361001, P.R. China E-mail: huquv7@163.com

Key words: dexmedetomidine, elderly colorectal cancer, postoperative cognitive dysfunction, analysis of influencing factors
$(\mathrm{P}<0.05)$. Dexmedetomidine can significantly improve postoperative cognitive dysfunction in elderly patients with colorectal cancer, and the occurrence of cognitive dysfunction can be affected by age, duration of anesthesia, intraoperative blood loss and the high expression of IL-6 and S-100 $\beta$.

\section{Introduction}

Colorectal cancer, a malignant tumor of the digestive system, has gradually increased in the elderly (1). Due to the underlying diseases and weakened immune function, the level of tolerance is weakened in elderly patients during surgery, therefore, it requires higher safety during surgery (2). Laparoscopy was adopted in clinical practice in 1991 (3). It is the main method for colorectal cancer surgery due mainly to the small trauma (4). Postoperative cognitive dysfunction (POCD) often appears in elderly patients undergoing large and mediumsized surgery under general anesthesia, with symptoms such as confusion, disorientation, and memory impairment (5). Due to the long anesthesia duration and the serious trauma caused by radical resection of colorectal cancer, the risk of POCD in elderly patients is greatly increased (6). Moreover, some data have shown that the mechanism of postoperative cognitive dysfunction is clearly related to the inflammatory response of the body, and it is more common in cardiothoracic surgery, abdominal surgery and other major operations (7).

Dexmedetomidine, a novel selective alpha 2 adrenergic receptor agonist, is effective in reducing stress response and can reduce the use of opioids and section of pro-inflammatory cytokines, thereby protecting the brain (8). Findings have shown that, the cognitive function of dexmedetomidine is enhanced after splenectomy in older rats (9). In addition, the high dosages of dexmedetomidine have the potential to prevent POCD (10).

POCD is a common complication of postoperative anesthesia in the elderly, and the factors affecting its onset are still unclear. The present study aimed to provide a reference for the clinical study of dexmedetomidine anesthesia for cognitive function dysfunction and its influencing factors in elderly colorectal cancer patients. 


\section{Materials and methods}

General information. One hundred and forty patients with radical colorectal cancer under general anesthesia were enrolled in Guizhou Provincial People's Hospital (Guiyang, China), from March 2012 to June 2015, including 80 patients in the dexmedetomidine group, with 51 males and 29 females, aged $73.76 \pm 14.54$ years, weight $56.76 \pm 10.12 \mathrm{~kg}$, with the disease duration of $0.71 \pm 0.27$ years, and 60 cases in the saline group, including 40 males and 20 females, with an average age of $74.09 \pm 13.87$ years, weight between $57.87 \pm 9.98 \mathrm{~kg}$, and the disease duration was $0.68 \pm 0.18$ years.

Inclusion criteria were: patients whose preoperative or intraoperative pathology were confirmed as colorectal cancer; patients who actively received and cooperated with the treatment; patients with complete data; patients without serious immune system diseases; patients whose ASA was in grade II-III (aged 60-85 years), with normal cognitive function (MMSE score $>27$ points).

Exclusion criteria were: Patients with central nervous system conditions and mental illness, taking sedatives, antidepressants, high blood pressure, diabetes, coronary heart disease, cerebral infarction and liver and kidney dysfunction and other prognostic diseases; patients undergoing radiotherapy and chemotherapy before surgery.

The study was approved by the Ethics Committee of Guizhou Provincial People's Hospital and the experimental content of the patients was described in detail. The patients agreed and signed a complete informed consent form.

Anesthesia method. All patients who underwent general anesthesia were applied with an endotracheal intubation procedure and pre-operative medication was avoided. Detection of vital signs such as heart rate (HR), electrocardiogram (ECG), non-invasive blood pressure (NIBP), pulse oxygen saturation $\left(\mathrm{SpO}_{2}\right)$ and end-tidal carbon dioxide $\left(\mathrm{PetCO}_{2}\right)$ were performed on patients during operation. In addition, Aspect-1000 were connected to monitor the bispectral index (BIS), then the peripheral venous access was established. Intravenous injection of $0.04 \mathrm{mg} / \mathrm{kg}$ midazolam (Jiangsu Enhua Pharmaceutical Group Co., Ltd., Jiangsu, China, batch number 080101), $4 \mu \mathrm{g} / \mathrm{kg}$ of fentanyl (Yichang Renfu Pharmaceutical Co., Ltd., Yichang, China, National Pharmaceutical Standard H42022076), 0.5-1.5 mg/kg of propofol (Xi'an Libang Pharmaceutical Co., Ltd., Xi'an, China, National Pharmaceutical Standard $\mathrm{H} 20040300$ ) and $0.15 \mathrm{mg} / \mathrm{kg}$ cis-atracurium (Jiangsu Hengrui Pharmaceutical Co., Ltd., Jiangsu, China, National Pharmaceutical Standard H20060869). Intravenous infusion of remifentanil $0.04-0.4 \mu \mathrm{g} /(\mathrm{kg} \cdot \mathrm{min})$ and propofol $1.5-2.5 \mathrm{mg} /(\mathrm{kg} \cdot \mathrm{h})$ were continuously applied in order to maintain the effectiveness of anesthesia during the operation, also intravenous injection of cis-atracurium were intermittent. The effectiveness of anesthesia was adjusted during the procedure and the BIS was maintained between 40 and 50; the breathing parameters were adjusted and the $\mathrm{PetCO}_{2}$ was maintained at $35-45 \mathrm{mmHg}$. In the study group, $200 \mu \mathrm{g}$ of dexmedetomidine (batch number: H20110085, Jiangsu Hengrui Pharmaceutical Co., Ltd.) was diluted to $50 \mathrm{ml}$ (prepared concentration of $4 \mu \mathrm{g} / \mathrm{ml}$ ) using physiological saline. The general anesthesia-induced tracheal intubation was started, and $1 \mu \mathrm{g} / \mathrm{kg}$ dexmedetomidine hydrochloride was intravenously pumped in $15 \mathrm{~min}$, and then the pump was maintained at $0.2-0.7 \mu \mathrm{g} /(\mathrm{kg} \cdot \mathrm{h})$. In addition, the infusion rate was adjusted according to changes in the patient's heart rate and blood pressure. Dexmedetomidine was discontinued $30 \mathrm{~min}$ before the end of the procedure. In the control group, the same amount of normal saline was injected in the intravenous pump at the corresponding time.

Serum collection. Peripheral blood $(2 \mathrm{ml})$ was collected on the 1st day before and 1st and 3rd day after surgery during fasting period, placed in an anticoagulation tube and sent to the laboratory. After coagulation for $60 \mathrm{~min}\left(20-25^{\circ} \mathrm{C}\right)$, it was centrifuged at $2,600 \mathrm{x}$ f for $10 \mathrm{~min}$ at $4^{\circ} \mathrm{C}$. The supernatant was collected at $-80^{\circ} \mathrm{C}$ to be tested, avoiding repeated freezing-thawing.

Determination of $S-100 \beta$ protein $(S-100 \beta)$ and interleukin-6 (IL-6) in serum by enzyme-linked immunosorbent assay (ELISA). S-100 $\beta$, IL-6 ELISA kit was purchased from Mo Shake Biological Co., Ltd., using the BS-1101 ELISA analyzer (Beyotime, Shanghai, China) for detection. $50 \mu \mathrm{l}$ of the standard was added to the wells that were coated with the enzyme label, then $40 \mu \mathrm{l}$ of the sample dilution was added to the wells of the samples, and $10 \mu \mathrm{l}$ of the sample to be tested was added (sample dilution ratio was 5 times). During the operation process, touching the wall of the well was avoided, the well was gently shaken, the reaction well was sealed with film, and then incubated in a water bath or incubator at $37^{\circ} \mathrm{C}$ for $30 \mathrm{~min}$. The sealing film was carefully uncovered, the liquid was discarded, and the film was dried with absorbent paper, and each well was filled with the washing solution. After standing for $30 \mathrm{sec}$, this step was repeated five times and then left to dry. In addition to the blank wells (the blank control wells were identical to the above steps, but without the enzyme-labeled reagents and samples), $50 \mu \mathrm{l}$ of the enzyme-labeled reagent was added to each well, and the mixture was incubated at $37^{\circ} \mathrm{C}$ for $30 \mathrm{~min}$ and then washed. Substrate A and B (50 $\mu$ l of each) was added to each well, and the color was developed at $37^{\circ} \mathrm{C}$ for $15 \mathrm{~min}$ in the dark. Stop solution $(50 \mu \mathrm{l})$ was added to each well, and the wells were zeroed with a blank well, and the absorbance (OD value) of each well was measured at a wavelength of $450 \mathrm{~nm}$ in $25 \mathrm{~min}$. Then the content of S-100 $\beta$ and IL-6 in the serum was calculated.

Observation indices. The mini mental state examination (MMSE) was performed 1 day before surgery, and repeated 1 day and 3 days after surgery. The score was divided into 30 points, of which 28 to 30 points indicate normal cognition, 24-27 are classified as mild cognitive dysfunction, 19-23 as moderate cognitive dysfunction, and $0-18$ as severe cognitive dysfunction (11). The incidence of POCD was compared between the two groups. The changes of S-100 $\beta$ and IL-6 levels before and after surgery were observed. The factors that contributed to the occurrence of POCD were analysed.

Statistical analysis. Statistical analysis of experimental data was performed using SPSS 19.0 software system (IBM Corp., Armonk, NY, USA), [n (\%)] was used to represent the count data, the chi-square test was used for comparison between the 
Table I. Comparison of clinical data and surgery conditions (mean $\pm \mathrm{SD}$ )/[n (\%)].

\begin{tabular}{|c|c|c|c|c|}
\hline Characteristics & $\begin{array}{l}\text { Experiment } \\
\text { group }(n=80)\end{array}$ & $\begin{array}{c}\text { Control } \\
\text { group }(n=60)\end{array}$ & $\chi^{2 / t}$ value & P-value \\
\hline Sex & & & 0.128 & 0.720 \\
\hline Male & $51(63.8)$ & $40(66.7)$ & & \\
\hline Female & $29(36.2)$ & $20(33.3)$ & & \\
\hline Age (years) & $73.76 \pm 14.54$ & $74.09 \pm 13.87$ & 0.136 & 0.892 \\
\hline Weigh (kg) & $56.76 \pm 10.12$ & $57.87 \pm 9.98$ & 0.646 & 0.519 \\
\hline Height (cm) & $167.65 \pm 12.76$ & $168.09 \pm 11.98$ & 0.207 & 0.836 \\
\hline Disease duration (years) & $0.71 \pm 0.27$ & $0.68 \pm 0.18$ & 0.745 & 0.458 \\
\hline Smoking status & & & 0.088 & 0.766 \\
\hline Smoking & $34(42.5)$ & $24(40.0)$ & & \\
\hline Non-smoking & $46(57.5)$ & $36(60.0)$ & & \\
\hline Alcoholism & & & 0.625 & 0.429 \\
\hline Alcoholic & $44(55.0)$ & $37(61.7)$ & & \\
\hline Non-alcoholic & $36(45.0)$ & $23(38.3)$ & & \\
\hline Operation time (min) & $182.67 \pm 24.76$ & $180.98 \pm 23.79$ & 0.406 & 0.685 \\
\hline Anesthesia time (h) & $188.27 \pm 54.65^{\mathrm{a}}$ & $211.12 \pm 79.98$ & 2.007 & $0.047^{\mathrm{a}}$ \\
\hline Intraoperative blood loss (ml) & $367.09 \pm 151.12^{\mathrm{a}}$ & $429.76 \pm 217.98$ & 2.008 & $0.047^{\mathrm{a}}$ \\
\hline
\end{tabular}

${ }^{\mathrm{a}} \mathrm{P}<0.05$, compared to the control group.

Table II. Comparison of MMSE scores between the two groups at different times.

\begin{tabular}{lccc}
\hline & $\begin{array}{c}1 \text { day } \\
\text { before } \\
\text { surgery }\end{array}$ & $\begin{array}{c}1 \text { day } \\
\text { after } \\
\text { surgery }\end{array}$ & $\begin{array}{c}3 \text { days } \\
\text { after } \\
\text { surgery }\end{array}$ \\
\hline Experiment group & $28.93 \pm 1.25$ & $26.76 \pm 1.67^{\mathrm{a}}$ & $28.11 \pm 2.01^{\mathrm{a}}$ \\
Control group & $28.89 \pm 1.22$ & $24.15 \pm 1.98^{\mathrm{a}, \mathrm{b}}$ & $26.09 \pm 1.78^{\mathrm{a}, \mathrm{b}}$ \\
t value & 0.189 & 8.448 & 6.176 \\
P-value & 0.850 & $<0.001$ & $<0.001$ \\
\hline
\end{tabular}

${ }^{a} \mathrm{P}<0.05$, comparison with the same group 1 day before surgery; ${ }^{\mathrm{b}} \mathrm{P}<0.05$, comparison with the experiment group at the same time.

groups. The measurement data were expressed as mean $\pm \mathrm{SD}$. The t-test was used to compare two groups, and the analysis of variance was used for comparison between multiple groups. The main relevant factors were analyzed by logistic regression The difference was statistically significant at $\mathrm{P}<0.05$.

\section{Results}

Comparison of general information. There was no significant difference between the experiment group and the control group in terms of sex, age, weight, height, duration of illness, smoking status and alcoholism $(\mathrm{P}>0.05)$. The surgical procedure of the two groups were compared, and there was no significant difference in the operation time between the experiment and control groups $(\mathrm{P}>0.05)$. The anesthesia time and intraoperative blood
Table III. Comparison of POCD status between the two groups.

\begin{tabular}{lcc}
\hline Group & $\begin{array}{c}1 \text { day } \\
\text { after } \\
\text { surgery }\end{array}$ & $\begin{array}{c}3 \text { days } \\
\text { after } \\
\text { surgery }\end{array}$ \\
\hline Experiment group $(\mathrm{n}=80)$ & $7(8.75 \%)$ & $0(0.00 \%)$ \\
Control group $(\mathrm{n}=60)$ & $13(21.67 \%)$ & $8(13.33 \%)$ \\
$\chi^{2}$ value & 4.672 & 11.31 \\
P-value & 0.031 & 0.0008 \\
\hline
\end{tabular}

loss in the experiment group were significantly lower than those in the control group $(\mathrm{P}<0.05)$ (Table I).

MMSE scores between two groups at different times. There was no significant difference in MMSE score between the experiment group and the control group before surgery $(\mathrm{P}>0.05)$. The MMSE scores of the two groups on the 1st and 3rd day after surgery were lower than those before surgery $(\mathrm{P}<0.05)$. The MMSE scores of the control group on the 1st day and 3rd day after surgery were significantly lower than those of the experiment group $(\mathrm{P}<0.05)$ (Table II).

Comparison of POCD status between the two groups of patients. There were $7(8.75 \%)$ cases of POCD in the experiment group on the 1st day after surgery, and 13 (21.67\%) cases of POCD in the control group, there was no POCD in the experiment group 3 days after surgery, and $8(13.33 \%)$ cases in the control group, and there was a significant difference between the two groups $(\mathrm{P}<0.05)$ (Table III). 
Table IV. Comparison of general data of patients with POCD and non-POCD after $5 \mathrm{~h}$ of surgery.

\begin{tabular}{|c|c|c|c|c|}
\hline Characteristics & $\begin{array}{c}\text { POCD } \\
\text { group }(n=20)\end{array}$ & $\begin{array}{c}\text { Non-POCD } \\
\text { group }(n=120)\end{array}$ & $\chi^{2}$ value & P-value \\
\hline Sex & & & 1.026 & 0.311 \\
\hline Male & $15(75.0)$ & $76(63.3)$ & & \\
\hline Female & $5(25.0)$ & $44(36.7)$ & & \\
\hline Age & & & 23.51 & $<0.001$ \\
\hline$<70$ & $4(20.0)$ & $90(75.0)$ & & \\
\hline$\geq 70$ & $16(80.0)$ & $30(25.0)$ & & \\
\hline Smoking status & & & 0.020 & 0.889 \\
\hline Smoking & $8(40.0)$ & $50(41.7)$ & & \\
\hline Non-smoking & $12(60.0)$ & $70(58.3)$ & & \\
\hline Alcoholism & & & 0.488 & 0.485 \\
\hline Alcoholic & $13(65.0)$ & $68(56.7)$ & & \\
\hline Non-alcoholic & $7(35.0)$ & $52(43.3)$ & & \\
\hline Anesthesia duration & & & 25.16 & $<0.001$ \\
\hline$\geq 3 \mathrm{~h}$ & $18(90.0)$ & $37(30.8)$ & & \\
\hline$<3 \mathrm{~h}$ & $2(10.0)$ & $83(69.2)$ & & \\
\hline Intraoperative blood loss & & & 19.65 & $<0.001$ \\
\hline$\geq 350 \mathrm{ml}$ & $15(75.0)$ & $30(25.0)$ & & \\
\hline$<350 \mathrm{ml}$ & $5(25.0)$ & $90(75.0)$ & & \\
\hline IL-6 & & & 22.55 & $<0.001$ \\
\hline Highly expressed & $16(80.0)$ & $31(25.8)$ & & \\
\hline Lowly expressed & $4(20.0)$ & $89(74.2)$ & & \\
\hline $\mathrm{S}-100 \beta$ & & & 43.14 & $<0.001$ \\
\hline Highly expressed & $18(90.0)$ & $22(18.3)$ & & \\
\hline Lowly expressed & $2(10.0)$ & $98(81.7)$ & & \\
\hline
\end{tabular}

Table V. Variables and valuations.

\begin{tabular}{lc}
\hline Variable & Valuations \\
\hline Age & $<70: 1, \geq 70: 2$ \\
Educational level & $\leq 9: 1,>9: 2$ \\
Anesthesia duration & $\geq 3 \mathrm{~h}: 1,<3 \mathrm{~h}: 2$ \\
Intraoperative blood loss & $\geq 350 \mathrm{ml}: 1,<350 \mathrm{ml}: 2$ \\
IL-6 & Highly expressed $(\geq 91.28 \mathrm{pg} / \mathrm{ml}): 1$, \\
& Lowly expressed $(<91.28 \mathrm{pg} / \mathrm{ml}): 2$ \\
S-100 & Highly expressed $(\geq 3.46 \mu \mathrm{g} / \mathrm{l}): 1$, \\
& Lowly expressed $(<3.46 \mu \mathrm{g} / \mathrm{l}): 2$ \\
\hline
\end{tabular}

Comparison of serum IL-6 and S-100 $\beta$ levels in the two groups. There was no significant difference in serum IL-6 and $\mathrm{S}-100 \beta$ levels between the two groups before surgery $(\mathrm{P}>0.05)$. The levels of serum IL-6 and S-100 $\beta$ in the two groups were increased compared with those 1 day and 3 days before surgery, and the difference was statistically significant $(\mathrm{P}<0.05)$. The levels of serum IL-6 and S-100 $\beta$ in the control group on the 1st and 3rd day after surgery were significantly higher than those in the experiment group $(\mathrm{P}<0.05)$ (Figs. 1 and 2).
Logistic regression analysis of POCD. The clinical data of all subjects were analysed 1 day after surgery, the clinical data of patients with POCD and non-POCD patients 1 day after surgery were analyzed by univariate analysis, the age, duration of anesthesia, intraoperative blood loss, IL-6 and S-100 $\beta$ expression were the influencing factors of POCD. Subsequently, multivariate Cox regression analysis of different indicators showed that age $\geq 70$ years, anesthesia duration $\geq 3 \mathrm{~h}$, intraoperative blood loss $\geq 350 \mathrm{ml}$, the high expressions of IL-6 and $S-100 \beta$ were important factors related to the occurrence of POCD $(\mathrm{P}<0.05)$ (Tables IV-VI).

\section{Discussion}

Colorectal cancer is a common malignant tumor. With the continuous improvement of living standards, environmental pollution, and changing lifestyles as well as eating habits, the incidence and mortality of colorectal cancer have been on the increase. In 2015, there were 376,000 new cases of colorectal cancer, which caused 191,000 deaths (12). The incidence of colorectal cancer is related to dietary structure, chronic inflammation of the intestine, heredity, colorectal adenoma and other factors $(13,14)$. Patients with colorectal cancer are often treated with radical surgery. Laparoscopic surgery is less traumatic than the traditional surgery, and has 
Table VI. Multi-factor Cox analysis.

\begin{tabular}{lccccr}
\hline & $\beta$ values & P-values & $\chi^{2}$ values & OR values & $95 \%$ CI \\
\hline Constant & -5.546 & 0.002 & 9.891 & 0.004 & \\
Age & -0.651 & 0.047 & 2.054 & 0.521 & $0.214-1.271$ \\
Anesthesia duration & 1.159 & 0.010 & 6.673 & 3.188 & $1.323-7.685$ \\
Intraoperative blood loss & 1.378 & 0.002 & 9.506 & 3.968 & $1.652-9.529$ \\
IL-6 & 0.927 & 0.042 & 4.127 & 2.527 & $1.033-6.180$ \\
S-100 $\beta$ & 1.042 & 0.030 & 4.732 & 2.835 & $1.109-7.249$ \\
\hline
\end{tabular}

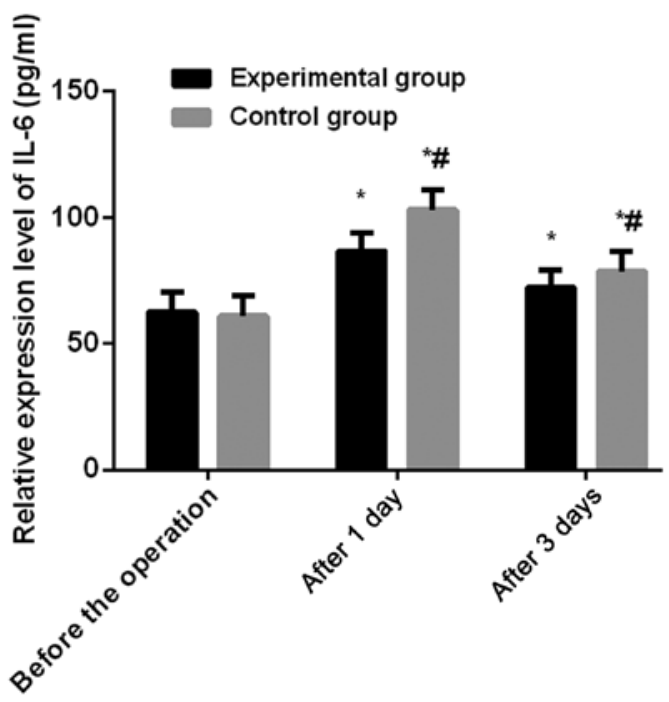

Figure 1. Comparison of serum IL-6 levels between the two groups. There was no significant difference in serum IL-6 levels between the two groups before surgery $(\mathrm{P}>0.05)$, serum IL-6 levels increased on the 1st and 3rd day after surgery compared with those before surgery, the difference was statistically significant $(\mathrm{P}<0.05)$, also serum IL-6 levels on the 1st and 3rd day after surgery were significantly higher than those in the experiment group $(\mathrm{P}<0.05) .{ }^{*} \mathrm{P}<0.05$ indicates the comparison 1 day before surgery; ${ }^{*} \mathrm{P}<0.05$ indicates comparison with the experiment group at the same time.

a better recovery after surgery (15). However, findings have shown that after surgery, clinical complications of POCD such as learning, memory, and perception appeared after surgery (16). The postoperative POCD in elderly patients is also closely related to inflammatory reaction, and has a certain relationship with the patient's preoperative history, surgical stimulation, age, anesthesia and other factors (17). Colorectal cancer is seriously affected by the anesthesia and the use of anesthetic drugs during the surgical treatment, resulting in the occurrence of inflammatory reactions, massive release of inflammatory mediators, and cognitive dysfunction in patients after surgery $(18,19)$.

Dexmedetomidine, an imidazole derivative and a dextrorotatory isomer of medetomidine, is a novel adrenal $\alpha 2$ receptor agonist with high selectivity. It can activate the $\mathrm{G}$ protein on the $\alpha 2$ adrenergic receptor in the central nervous system, and the release of norepinephrine is inhibited, which affects the sympathetic nervous system and exerts its sedative, anti-anxiety and analgesic effects $(20,21)$. It can activate the cholinergic anti-inflammatory pathway and downregulate inflammatory factors to exert anti-inflammatory effects (22).

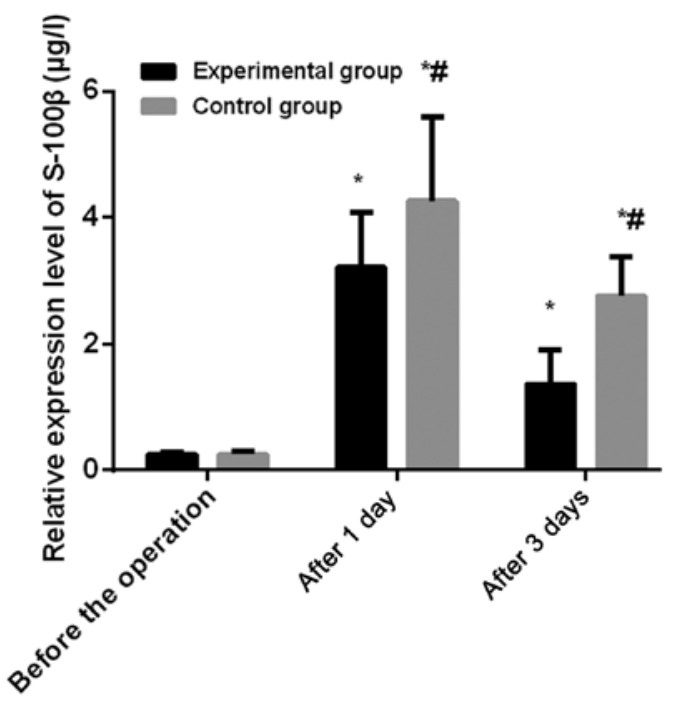

Figure 2. Comparison of serum S-100 $\beta$ levels between the two groups. There was no significant difference in serum S-100 $\beta$ levels between the two groups before surgery $(\mathrm{P}>0.05)$. The levels of serum $\mathrm{S}-100 \beta$ in the two groups were increased compared with those before surgery, and the difference was statistically significant $(\mathrm{P}<0.05)$. Serum $\mathrm{S}-100 \beta$ levels on the 1st and 3rd day after surgery were significantly higher than those in the experiment group $(\mathrm{P}<0.05) .{ }^{*} \mathrm{P}<0.05$ indicates the comparison 1 day before surgery; ${ }^{\#} \mathrm{P}<0.05$ indicates comparison with the experiment group at the same time.

Moreover, dexmedetomidine is widely used in clinical anesthesia, which can stabilize the patient's hemodynamics, reduce the incidence of adverse reactions as well as the use of sedative anesthetics. Moreover, it has a certain inhibitory effect on the stress response and secretion and release of inflammatory factors, and there is a certain protective effect on the brain and myocardium of patients, which significantly improves the occurrence of POCD (23).

As a polypeptide, cytokines function by regulating the physiological functions of the body (24). S-100 $\beta$ is a specific indicator for judging brain damage, which is mainly present in the central nervous system of the body (25). The binding of IL-6 to membrane receptors on the surface of tumor cells enables inducible proliferation of tumor cells, which in turn inhibits apoptosis of cells and causes postoperative damage (26).

The surgery of the two groups were compared, there was no significant difference in the surgery duration between the experiment group and the control group $(\mathrm{P}>0.05)$. The anesthesia time and intraoperative blood loss in the experiment group were significantly less than those in the control group $(\mathrm{P}<0.05)$. van Harten et al (27) found that the incidence 
of postoperative POCD in surgical patients has a certain relationship with surgical diseases and anesthetic drugs. This study showed that compared with the preoperative MMSE scores, the scores of MMSE after surgery for elderly colorectal cancer were significantly lower, and the decrease of MMSE score after dexmedetomidine was significantly reduced. The incidence of POCD on the 1st day and 3rd day after surgery was significantly lower in the experiment group than in the control group $(\mathrm{P}<0.05)$. This is consistent with the study by Chan et al (28). Intravenous injection of dexmedetomidine after anesthesia induction resulted in a significant reduction in postoperative mental confusion and POCD incidence. Findings have shown that inflammatory response as an independent factor often leading to the occurrence of POCD $(29,30)$, while S-100 $\beta$ protein is a good indicator of brain damage (31).

The high level of IL-6 reflects the strong surgical stress response (26). The results showed that there was no significant difference in serum IL-6 and S-100 $\beta$ levels between the two groups before surgery $(\mathrm{P}>0.05)$. The levels of serum IL- 6 and S-100 $\beta$ in the two groups were increased on the 1st and 3rd day after surgery, and the difference was statistically significant $(\mathrm{P}<0.05)$. The levels of serum IL-6 and S-100 $\beta$ in the control group on the 1st and 3rd day after surgery were significant higher than those in the experiment group $(\mathrm{P}<0.05)$. There are many reasons for cognitive dysfunction in patients after surgery, and the pathogenesis is still unclear. Age, preoperative underlying disease, type of surgery, duration of anesthesia, postoperative infection, respiratory complications, intraoperative anesthesia, and sedation of the patients may be associated with postoperative cognitive dysfunction (32). Ramlawi et al found that the severity and duration of the inflammatory response are related to POCD (33). In this study, multivariate Cox regression analysis found that in elderly people aged $>70$ years, anesthesia duration of more than $3 \mathrm{~h}$, intraoperative blood loss over $350 \mathrm{ml}$, high expression of IL- 6 and S-100 $\beta$ are important factors in the occurrence of POCD $(\mathrm{P}<0.05)$. This is consistent with other studies whereby the cognitive dysfunction is associated with advanced age, low level of education, high blood pressure comorbidities and long duration of anesthesia (34).

Many studies on the effects of dexmedetomidine on cognitive function have no definitive conclusions as the subjects were different, the dosages, timing, and methods used for dexmedetomidine were different. Further research on larger number of samples, and the mechanism of dexmedetomidine need to be carried out.

In summary, dexmedetomidine can significantly improve postoperative cognitive dysfunction in elderly patients with colorectal cancer. The occurrence of cognitive dysfunction is affected by the age, duration of anesthesia, intraoperative blood loss and high expression of IL- 6 and S-100ß.

\section{Acknowledgements}

Not applicable.

\section{Funding}

No funding was received.

\section{Availability of data and materials}

The datasets used and/or analyzed during the present study are available from the corresponding author on reasonable request.

\section{Authors' contributions}

JZ wrote the manuscript. JZ, GL and FZ were responsible for ELISA. HF, DZ and SL analyzed and interpreted the patients' data. BC and HX helped with statistical analysis. All the authors read and approved the final manuscript.

\section{Ethics approval and consent to participate}

The study was approved by the Ethics Committee of Guizhou Provincial People's Hospital (Guiyang, China). Patients who participated in this research had complete clinical data. Signed informed consents were obtained from the patients or the guardians.

\section{Patient consent for publication}

Not applicable.

\section{Competing interests}

The authors declare that they have no competing interests.

\section{References}

1. Vincent MD, Breadner D, Cripps MC, Jonker DJ, Klimo P, Biagi JJ, Lam W, O'Connell A, Whiston F, Stitt L, et al: Phase I/II trial of dose-reduced capecitabine in elderly patients with advanced colorectal cancer. Curr Oncol 24: e261-e268, 2017.

2. Finlayson E, Zhao S and Varma MG: Outcomes after rectal cancer surgery in elderly nursing home residents. Dis Colon Rectum 55: 1229-1235, 2012.

3. Kennedy RH, Francis EA, Wharton R, Blazeby JM, Quirke P, West NP and Dutton SJ: Multicenter randomized controlled trial of conventional versus laparoscopic surgery for colorectal cancer within an enhanced recovery programme: EnROL. J Clin Oncol 32: 1804-1811, 2014.

4. Shen F, Cai WS, Li JL, Feng Z, Liu QC, Xiao HQ, Cao J and $\mathrm{Xu}$ B: Synergism from the combination of ulinastatin and curcumin offers greater inhibition against colorectal cancer liver metastases via modulating matrix metalloproteinase-9 and E-cadherin expression. Onco Targets Ther 7: 305-314, 2014.

5. Feinkohl I, Winterer G, Spies CD and Pischon T: Cognitive reserve and the risk of postoperative cognitive dysfunction. Dtsch Arztebl Int 114: 110-117, 2017.

6. Visovatti MA, Reuter-Lorenz PA, Chang AE, Northouse L and Cimprich B: Assessment of cognitive impairment and complaints in individuals with colorectal cancer. Oncol Nurs Forum 43: 169-178, 2016.

7. Louzon P, Jennings H, Ali M and Kraisinger M: Impact of pharmacist management of pain, agitation, and delirium in the intensive care unit through participation in multidisciplinary bundle rounds. Am J Health Syst Pharm 74: 253-262, 2017.

8. Tasdogan M, Memis D, Sut N and Yuksel M: Results of a pilot study on the effects of propofol and dexmedetomidine on inflammatory responses and intraabdominal pressure in severe sepsis. J Clin Anesth 21: 394-400, 2009.

9. Xiong B, Shi Q and Fang H: Dexmedetomidine alleviates postoperative cognitive dysfunction by inhibiting neuron excitation in aged rats. Am J Transl Res 8: 70-80, 2016.

10. Fu C, Dai X, Yang Y, Lin M, Cai Y and Cai S: Dexmedetomidine attenuates lipopolysaccharide-induced acute lung injury by inhibiting oxidative stress, mitochondrial dysfunction and apoptosis in rats. Mol Med Rep 15: 131-138, 2017. 
11. Dufouil C, Clayton D, Brayne C, Chi LY, Dening TR, Paykel ES, O'Connor DW, Ahmed A, McGee MA and Huppert FA: Population norms for the MMSE in the very old: Estimates based on longitudinal data. Mini-Mental State Examination. Neurology 55: 1609-1613, 2000.

12. Chen W, Zheng R, Baade PD, Zhang S, Zeng H, Bray F, Jemal A Yu XQ and He J: Cancer statistics in China, 2015. CA Cancer J Clin 66: 115-132, 2016.

13. Allemani C, Rachet B, Weir HK, Richardson LC, Lepage C, Faivre J, Gatta G, Capocaccia R, Sant M, Baili P, et al: Colorectal cancer survival in the USA and Europe: A CONCORD highresolution study. BMJ Open 3: e003055, 2013.

14. Citronberg J, Bostick R, Ahearn T, Turgeon DK, Ruffin MT, Djuric Z, Sen A, Brenner DE and Zick SM: Effects of ginger supplementation on cell-cycle biomarkers in the normalappearing colonic mucosa of patients at increased risk for colorectal cancer: Results from a pilot, randomized, and controlled trial. Cancer Prev Res (Phila) 6: 271-281, 2013

15. Galsky MD, Stensland KD, Moshier E, Sfakianos JP, McBride RB, Tsao CK, Casey M, Boffetta P, Oh WK, Mazumdar M, et al: Effectiveness of adjuvant chemotherapy for locally advanced bladder cancer. J Clin Oncol 34: 825-832, 2016.

16. Güclü CY, Ünver S, Aydınlı B, Kazancı D, Dilber E and Özgök A: The effect of sevoflurane vs. TIVA on cerebral oxygen saturation during cardiopulmonary bypass - randomized trial. Adv Clin Exp Med 23: 919-924, 2014.

17. de Tournay-Jetté E, Dupuis G, Bherer L, Deschamps A, Cartier R and Denault A: The relationship between cerebral oxygen saturation changes and postoperative cognitive dysfunction in elderly patients after coronary artery bypass graft surgery. J Cardiothorac Vasc Anesth 25: 95-104, 2011.

18. Gruppo AIR: Consensus document: a model of integrated management of patients with psycomotor agitation. Riv Psichiatr 51: 238-250, 2016 (In Italian).

19. Zhang J, Zhang J, Yu P, Chen M, Peng Q, Wang Z and Dong N: Remote ischaemic preconditioning and sevoflurane postconditioning synergistically protect rats from myocardial injury induced by ischemia and reperfusion partly via inhibition TLR4/ MyD88/NF- $\kappa \mathrm{B}$ signaling pathway. Cell Physiol Biochem 41: 22-32, 2017.

20. Ohtani N, Kida K, Shoji K, Yasui Y and Masaki E: Recovery profiles from dexmedetomidine as a general anesthetic adjuvant in patients undergoing lower abdominal surgery. Anesth Analg 107: 1871-1874, 2008

21. Yildiz M, Tavlan A, Tuncer S, Reisli R, Yosunkaya A and Otelcioglu S: Effect of dexmedetomidine on haemodynamic responses to laryngoscopy and intubation: Perioperative haemodynamics and anaesthetic requirements. Drugs R D 7: 43-52, 2006.
22. Pavlov VA and Tracey KJ: The cholinergic anti-inflammatory pathway. Brain Behav Immun 19: 493-499, 2005.

23. Teegarden BM and Prough DS: Delirium: Getting back on track. Crit Care Med 44: 1265-1266, 2016

24. Li QY, Xu HY and Yang HJ: Effect of proinflammatory factors TNF- $\alpha$, IL-1 $\beta$, IL- 6 on neuropathic pain. Zhongguo Zhong Yao Za Zhi 42: 3709-3712, 2017 (In Chinese).

25. Yang B, Qian F, Li W, Li Y and Han Y: Effects of general anesthesia with or without epidural block on tumor metastasis and mechanisms. Oncol Lett 15: 4662-4668, 2018.

26. Liu F, Zhang J, Zeng XQ, Zhao YQ and Zuo YX: Application of general anesthesia combined with epidural anesthesia/analgesia in rehabilitation after gastric cancer resection. Zhonghua Yi Xue Za Zhi 97: 1089-1092, 2017 (In Chinese).

27. van Harten AE, Scheeren TW and Absalom AR: A review of postoperative cognitive dysfunction and neuroinflammation associated with cardiac surgery and anaesthesia. Anaesthesia 67: 280-293, 2012

28. Chan MT, Cheng BC, Lee TM and Gin T; CODA Trial Group: BIS-guided anesthesia decreases postoperative delirium and cognitive decline. J Neurosurg Anesthesiol 25: 33-42, 2013.

29. Barrientos RM, Hein AM, Frank MG, Watkins LR and Maier SF: Intracisternal interleukin-1 receptor antagonist prevents postoperative cognitive decline and neuroinflammatory response in aged rats. J Neurosci 32: 14641-14648, 2012.

30. Wu C, Wang R, Li X and Chen J: Preoperative serum microRNA-155 expression independently predicts postoperative cognitive dysfunction after laparoscopic surgery for colon cancer. Med Sci Monit 22: 4503-4508, 2016.

31. Wang XT, Lv M and Guo HY: Effects of epidural block combined with general anesthesia on antitumor characteristics of $\mathrm{T}$ helper cells in hepatocellular carcinoma patients. J Biol Regul Homeost Agents 30: 67-77, 2016.

32. Hanning CD: Postoperative cognitive dysfunction. Br J Anaesth 95: 82-87, 2005.

33. Ramlawi B, Rudolph JL, Mieno S, Feng J, Boodhwani M, Khabbaz K, Levkoff SE, Marcantonio ER, Bianchi C and Sellke FW: C-Reactive protein and inflammatory response associated to neurocognitive decline following cardiac surgery. Surgery 140: 221-226, 2006.

34. Fu M and Li D: General anesthesia combined with epidural anesthesia on the postoperative cognitive functions in pregnant women with dystocia. Exp Ther Med 16: 1149-1152, 2018. 